\title{
Donor/Acceptor Interactions in Self-Assembled Monolayers and Their Consequences on Interfacial Electron Transfer
}

\author{
Eden J. Pacsial, Daniel Alexander, Robert J. Alvarado, \\ Massimiliano Tomasulo and Françisco M. Raymo*
}

Center for Supramolecular Science, Department of Chemistry, University of Miami 1301 Memorial Drive, FL 33146-0431, USA

- Experimental Procedures for the Synthesis of 1

- Cyclic Voltammograms of the TTF Monolayers

- Cyclic Voltammograms and Impedance Response of $\mathrm{Ru}\left(\mathrm{NH}_{3}\right)_{6} \mathrm{Cl}_{3}$ at Bare and Hexadecanethiolate-Coated Gold

- Impedance Response of Ferrocene, Benzylviologen, TCNQ and TCNE at Bare Gold

- Cyclic Voltammograms of Benzylviologen, TCNQ and TCNE at Bare Gold

- Determination of $R_{\mathrm{CT}}$ from the Impedance Plots

\footnotetext{
${ }^{*}$ Corresponding author. Telephone: 3052842639

Fax: 3052844571

E-Mail: fraymo@miami.edu
} 


\section{Experimental Procedures for the Synthesis of 1}

4,5-Bis(2-Cyanoethylsulfanyl)-1,3-dithiole-2-thione $\quad(\boldsymbol{I}) .{ }^{1} \quad$ A solution of bis(tetraethylammonium)bis(thioxo-1,3-dithiole-4,5-dithiolato)zincate(II) (6.97 g, $1 \mathrm{mmol})$ and 3-bromopropionitrile $(6.49 \mathrm{~g}, 40 \mathrm{mmol})$ in $\mathrm{MeCN}(130 \mathrm{~mL})$ was heated for $1 \mathrm{~h}$ under reflux and $\mathrm{N}_{2}$. After cooling down to ambient temperature, the mixture was filtered and the solvent was distilled off under reduced pressure. The residue was dissolved in $\mathrm{CHCl}_{3}(500 \mathrm{~mL})$, washed with $\mathrm{H}_{2} \mathrm{O}(3 \times 200 \mathrm{~mL})$ and dried $\left(\mathrm{MgSO}_{4}\right)$ to yield $\boldsymbol{I}(5.84 \mathrm{~g}, 99 \%)$. FABMS: $\mathrm{m} / \mathrm{z}=$ $305[\mathrm{M}+\mathrm{H}]^{+} ;{ }^{1} \mathrm{H}-\mathrm{NMR}\left(\mathrm{CDCl}_{3}\right): \delta=3.14(4 \mathrm{H}, \mathrm{t}, J=7 \mathrm{~Hz}), 2.79(4 \mathrm{H}, \mathrm{t}, J=7$ $\mathrm{Hz}) ;{ }^{13} \mathrm{C}-\mathrm{NMR}\left(\mathrm{CDCl}_{3}\right): \delta=209.53,136.21,117.52,32.19,19.45$.

4-(2-Cyanoethylsulfanyl)-5-methylsulfanyl-1,3-dithiole-2-thione $\quad$ (II). ${ }^{1} \quad \mathrm{~A}$ solution of $\mathrm{CsOH} \cdot \mathrm{H}_{2} \mathrm{O}(3.32 \mathrm{~g}, 16 \mathrm{mmol})$ in degassed $\mathrm{MeOH}(25 \mathrm{~mL})$ was added to a solution of $\boldsymbol{I}(4.76 \mathrm{~g}, 16 \mathrm{mmol})$ in degassed $\mathrm{MeCN}(250 \mathrm{~mL})$ over 30 min at ambient temperature under $\mathrm{N}_{2}$. The mixture was stirred for a further $30 \mathrm{~min}$ and then MeI $(10 \mathrm{~mL}, 157 \mathrm{mmol})$ was added. After $1 \mathrm{~h}$ at ambient temperature and under $\mathrm{N}_{2}$, the solvent was distilled off under reduced pressure. The residue was dissolved in $\mathrm{CH}_{2} \mathrm{Cl}_{2}(300 \mathrm{~mL})$, washed with $\mathrm{H}_{2} \mathrm{O}$ $(3 \times 200 \mathrm{~mL})$, dried $\left(\mathrm{MgSO}_{4}\right)$ and purified by column chromatography $\left(\mathrm{SiO}_{2}\right.$, $\mathrm{CH}_{2} \mathrm{Cl}_{2}$ ) to yield II (3.85 g, 93\%). FABMS: $\mathrm{m} / \mathrm{z}=266[\mathrm{M}+\mathrm{H}]^{+} ;{ }^{1} \mathrm{H}-\mathrm{NMR}$ $\left(\mathrm{CDCl}_{3}\right): \delta=3.06(2 \mathrm{H}, \mathrm{t}, J=7 \mathrm{~Hz}), 2.73(2 \mathrm{H}, \mathrm{t}, J=7 \mathrm{~Hz}), 2.54(3 \mathrm{H}, \mathrm{s}) ;{ }^{13} \mathrm{C}-$ $\operatorname{NMR}\left(\mathrm{CDCl}_{3}\right): \delta=209.91,144.74,117.05,31.87,18.97,18.85$.

4-(2-Cyanoethylsulfanyl)-5-methylsulfanyl-1,3-dithiole-2-one (III). ${ }^{2}$ A solution of II $(0.50 \mathrm{~g}, 2 \mathrm{mmol})$ and $\left(\mathrm{MeCO}_{2}\right)_{2} \mathrm{Hg}(1.27 \mathrm{~g}, 4 \mathrm{mmol})$ in $\mathrm{CHCl}_{3} / \mathrm{MeCO}_{2} \mathrm{H}$ $(3: 1,20 \mathrm{~mL})$ was stirred for $16 \mathrm{~h}$ at ambient temperature under $\mathrm{N}_{2}$. The mixture was filtered through Celite, diluted with an aqueous solution of $\mathrm{NaHCO}_{3}(2 \mathrm{M}$, $600 \mathrm{~mL})$, washed with $\mathrm{H}_{2} \mathrm{O}(200 \mathrm{~mL})$ and dried $\left(\mathrm{MgSO}_{4}\right)$. The residue was purified by column chromatography $\left(\mathrm{SiO}_{2}, \mathrm{CHCl}_{3}\right)$ to yield $\mathbf{I I I}(225 \mathrm{mg}, 48 \%)$. FABMS: $m / z=249\left[\mathrm{M}^{+} ;{ }^{1} \mathrm{H}-\mathrm{NMR}\left(\mathrm{CDCl}_{3}\right): \delta=3.05(2 \mathrm{H}, \mathrm{t}, J=7 \mathrm{~Hz}), 2.72\right.$ $(2 \mathrm{H}, \mathrm{t}, J=7 \mathrm{~Hz}), 2.50(3 \mathrm{H}, \mathrm{s}) ;{ }^{13} \mathrm{C}-\mathrm{NMR}\left(\mathrm{CDCl}_{3}\right): \delta=189.02,135.92,118.18$, $117.53,31.89,19.40,19.03$.

4-(2-Cyanoethylsulfanyl)-5-methylsulfanyl-tetrathiafulvalene (1). ${ }^{3}$ A solution of 1,3-dithiole-2-thione ( $859 \mathrm{mg}, 6.40 \mathrm{mmol})$ in $\mathrm{P}(\mathrm{OMe})_{3}(7.94 \mathrm{mg}, 48 \mathrm{mmol}$, $5.66 \mathrm{~mL}$ ) was stirred for $10 \mathrm{~min}$ at $80^{\circ} \mathrm{C}$ under Ar. Then, III $(400 \mathrm{mg}$, $1.60 \mathrm{mmol}$ ) was added to the solution and the mixture was heated at $110^{\circ} \mathrm{C}$ for $3 \mathrm{~h}$. After cooling down to ambient temperature, the solvent was distilled under reduced pressure. The residue was purified by column chromatography $\left[\mathrm{SiO}_{2}\right.$, $\mathrm{PhMe} /$ hexane $(50: 50 \rightarrow 100: 0)]$ and crystallized from $\mathrm{CH}_{2} \mathrm{Cl}_{2} /$ hexane to give $\mathbf{1}$ $(102 \mathrm{mg}, 19 \%)$ as red orange needles. $\mathrm{mp}=78-79^{\circ} \mathrm{C}$; FABMS: $\mathrm{m} / \mathrm{z}=335$ $[\mathrm{M}]^{+} ;{ }^{1} \mathrm{H}-\mathrm{NMR}\left(\mathrm{CDCl}_{3}\right): \delta=6.33(2 \mathrm{H}, \mathrm{s}), 3.00(2 \mathrm{H}, \mathrm{t}, J=7 \mathrm{~Hz}), 2.68(2 \mathrm{H}, \mathrm{t}, J$ $=7 \mathrm{~Hz}), 2.45(3 \mathrm{H}, \mathrm{s}) ;{ }^{13} \mathrm{C}-\mathrm{NMR}\left(\mathrm{CDCl}_{3}\right): \delta=135.37,120.16,119.09,118.97$, $117.71,117.31,104.52,31.23,19.19,18.78$.
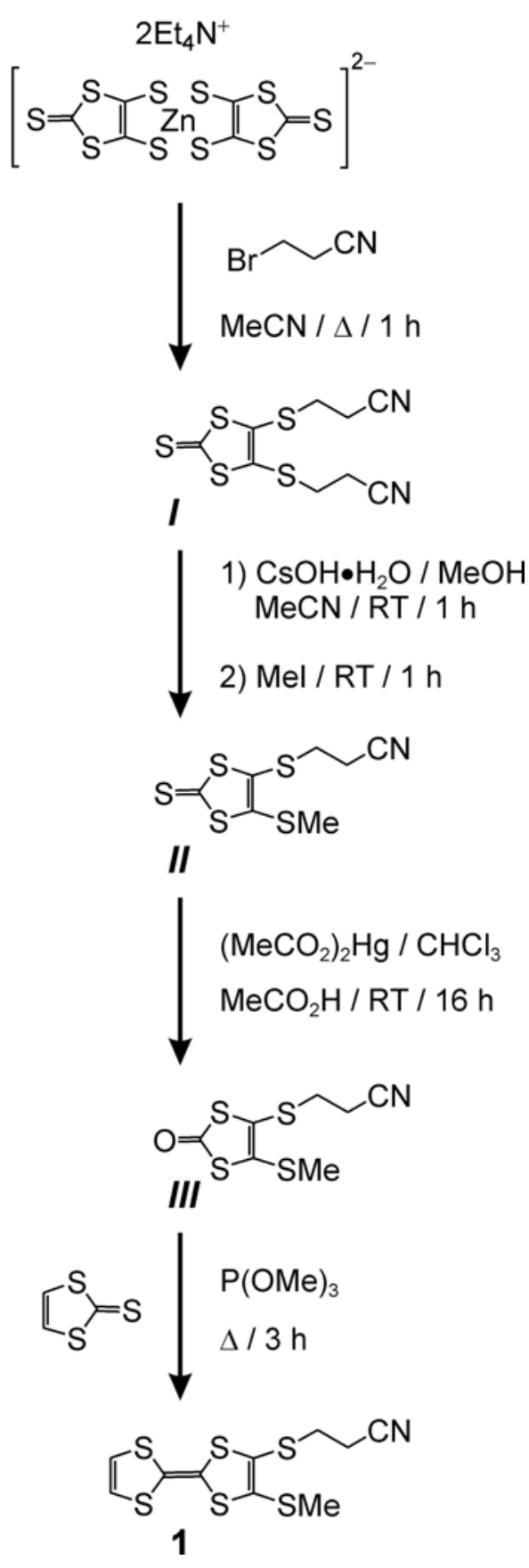

Figure S1. Synthesis of the TTF 1.

1 Simonsen, K. B.; Svenstrup, N.; Lau, J. ; Simonsen, O.; Mørk, P.; Kristensen, G. J.; Becher, J. Synthesis 1996, 407-418.

2 Lau, J.; Blanchard, P.; Riou, A.; Jubault, M.; Cava, M. P.; Becher, J. J. Org. Chem. 1997, 62, 4936-4942.

3 Bartlett, P. N.; Booth, S.; Caruana, D. J.; Kilburn, J. D.; Santamaria, C. Anal. Chem. 1997, 69, 734-742. 


\section{Cyclic Voltammograms of the TTF Monolayers}

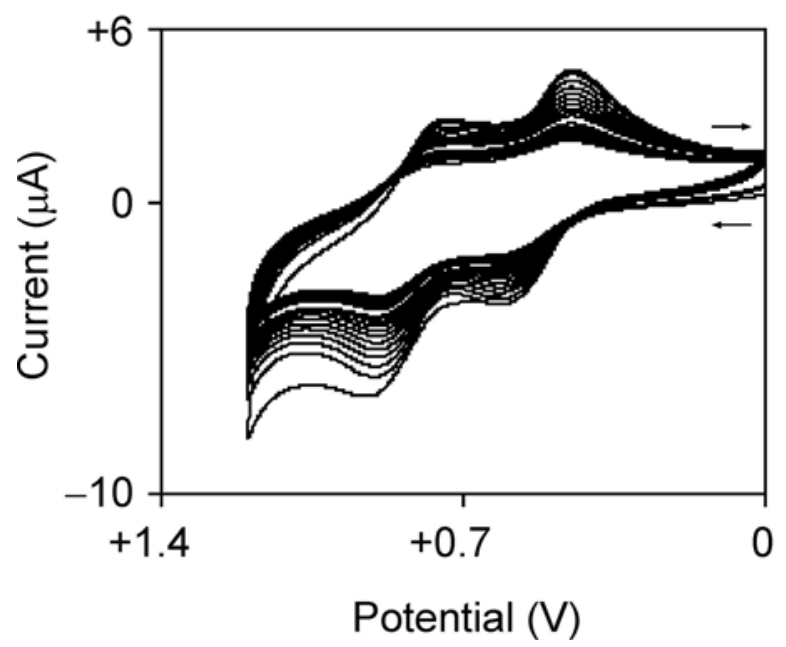

Figure S2. Twenty consecutive cyclic voltammograms $\left(0.1 \mathrm{M} \mathrm{Bu}_{4} \mathrm{NPF}_{6}, \mathrm{MeCN}, \mathrm{V}\right.$ vs. $\left.\mathrm{Ag} / \mathrm{AgCl}, 100 \mathrm{mV} \mathrm{s}^{-1}\right)$ recorded after the immersion of a gold working electrode in a MeCN solution of $4\left(1 \times 10^{-3} \mathrm{M}\right)$ for $3 \mathrm{~d}$ and copious rinsing of the electrode surface. 


\section{Cyclic Voltammograms and Impedance Response of $\mathrm{Ru}\left(\mathrm{NH}_{3}\right)_{6} \mathrm{Cl}_{3}$}

\section{at Bare and Hexadecanethiolate-Coated Gold}
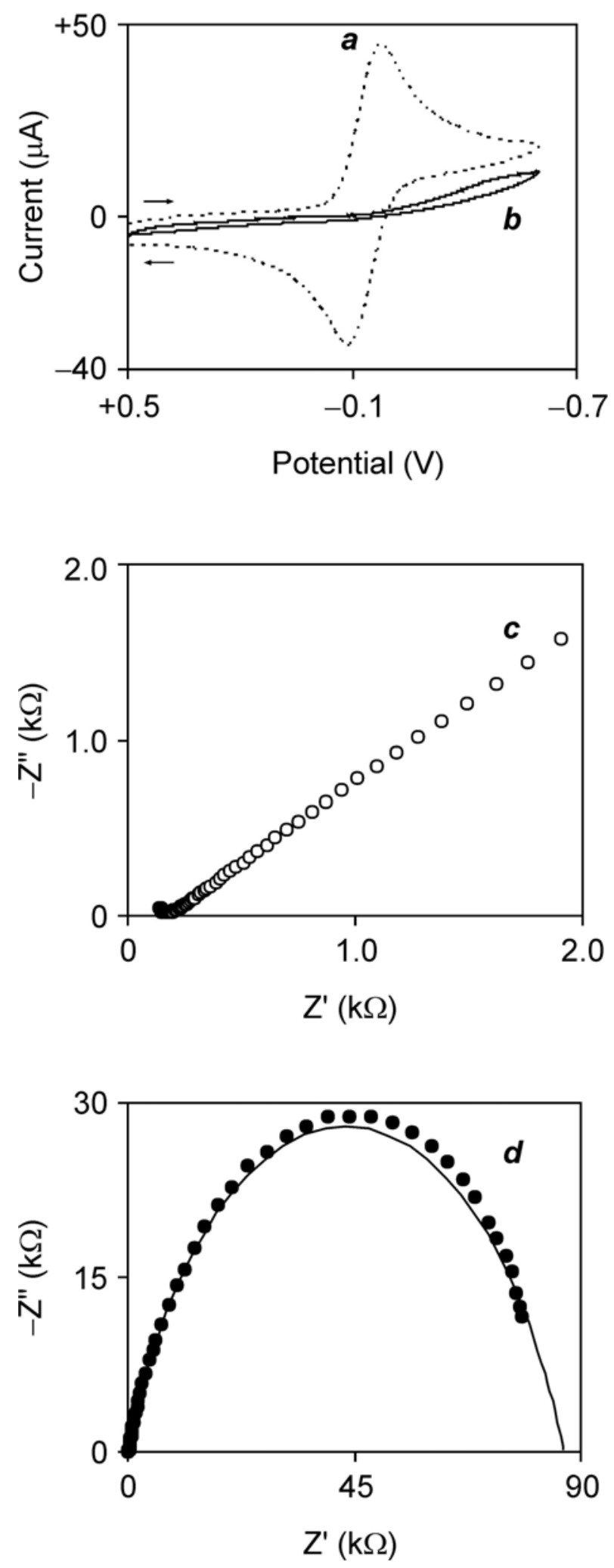

Figure S3. Cyclic voltammograms (V vs. $\mathrm{Ag} / \mathrm{AgCl}$, $\left.100 \mathrm{mV} \mathrm{s}^{-1}\right)$ and impedance plots $(-0.133 \pm 0.005 \mathrm{~V}$ vs. $\mathrm{Ag} / \mathrm{AgCl}, 100 \mathrm{kHz}-0.1 \mathrm{~Hz})$ of $\mathrm{Ru}\left(\mathrm{NH}_{3}\right)_{6} \mathrm{Cl}_{3}\left(1 \times 10^{-3} \mathrm{M}, 0.1 \mathrm{M}\right.$ $\mathrm{KCl}, \mathrm{H}_{2} \mathrm{O}$ ) recorded before ( $\boldsymbol{a}$ and $\boldsymbol{c}$ ) and after ( $\boldsymbol{b}$ and $\boldsymbol{d}$ ) the immersion of a gold working electrode in a $\mathrm{EtOH}$ solution of hexadecanethiol $\left(1 \times 10^{-3} \mathrm{M}\right)$ for $1 \mathrm{~d}$ and copious rinsing of the electrode surface. 
Impedance Response of Ferrocene, Benzylviologen, TCNQ and TCNE at Bare Gold
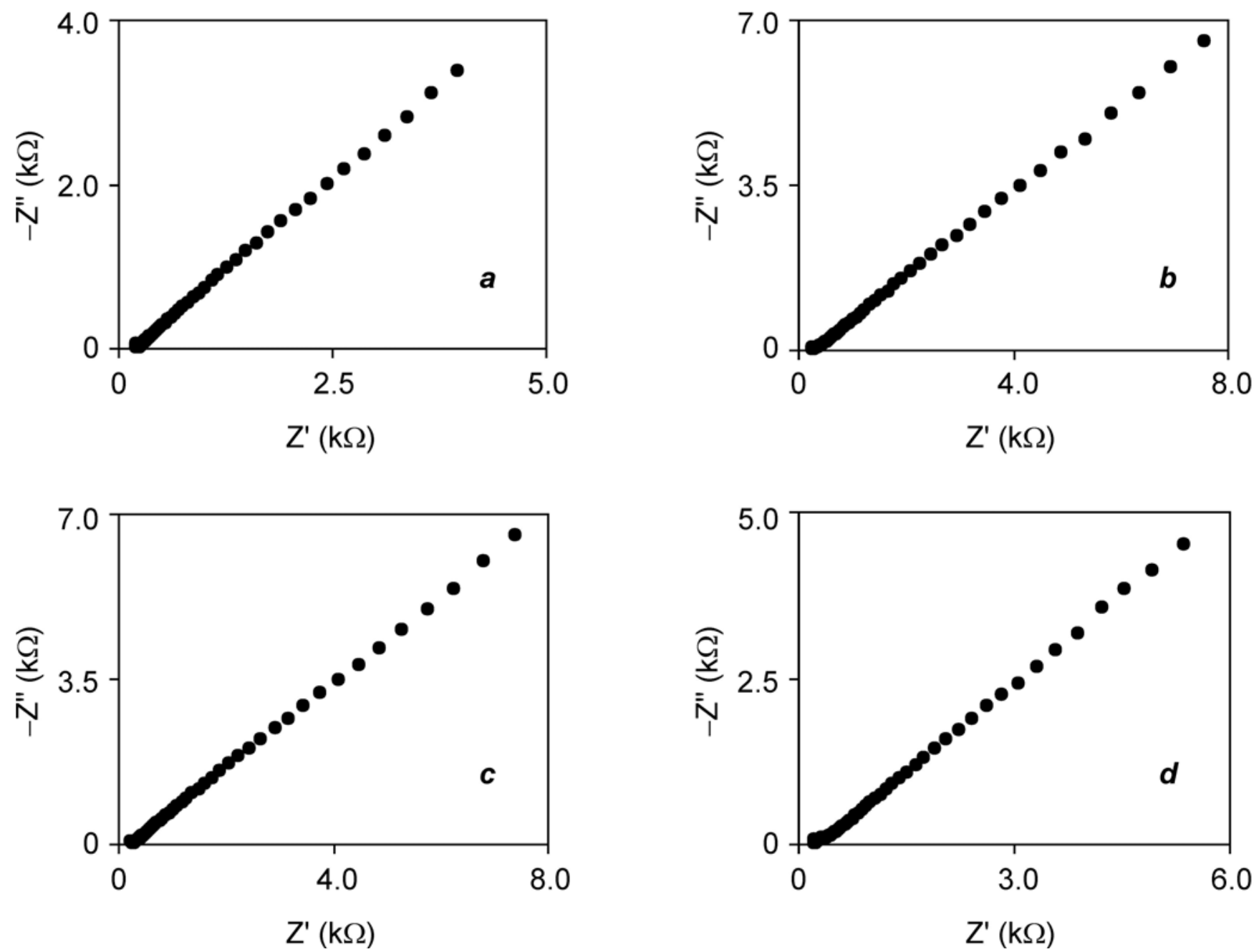

Figure S4. Impedance plots $\left(0.1 \mathrm{M} \mathrm{Bu}_{4} \mathrm{NPF}_{6}, \mathrm{MeCN}, \mathrm{V}\right.$ vs. $\left.\mathrm{Ag} / \mathrm{AgCl}, 100 \mathrm{kHz}-0.1 \mathrm{~Hz}, 1 \times 10^{-3} \mathrm{M}\right)$ of ferrocene $(\boldsymbol{a}$, $+0.457 \pm 0.005 \mathrm{~V})$, benzylviologen $(\boldsymbol{b},-0.316 \pm 0.005 \mathrm{~V})$, TCNQ $(\boldsymbol{c},+0.249 \pm 0.005 \mathrm{~V})$ and TCNE $(\boldsymbol{d},+0.292 \pm 0.005 \mathrm{~V})$ recorded with bare gold working electrodes. 


\section{Cyclic Voltammograms of Benzylviologen, TCNQ and TCNE at Bare Gold}
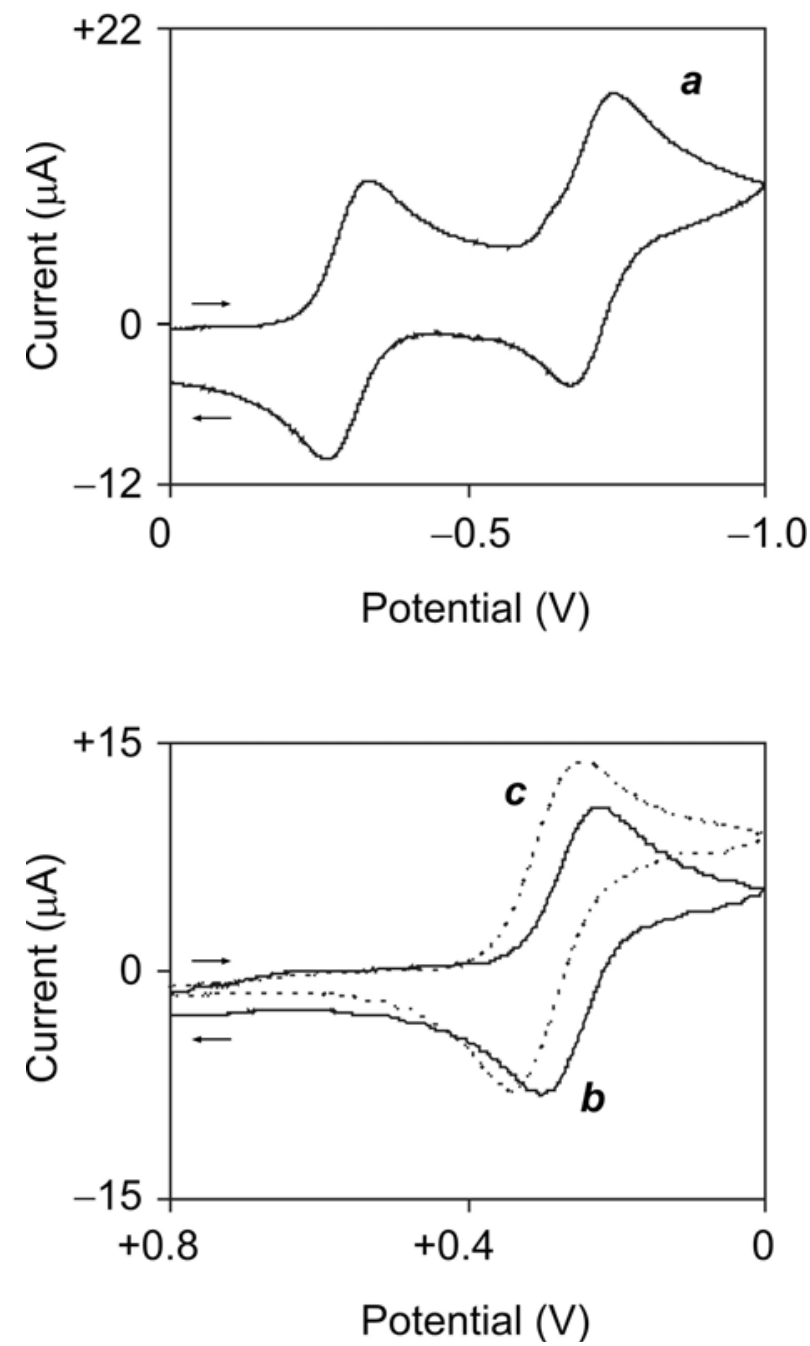

Figure S5. Cyclic voltammograms $\left(0.1 \mathrm{M} \mathrm{Bu}_{4} \mathrm{NPF}_{6}\right.$, $\mathrm{MeCN}, \mathrm{V}$ vs. $\left.\mathrm{Ag} / \mathrm{AgCl}, 100 \mathrm{mV} \mathrm{s}^{-1}, 1 \times 10^{-3} \mathrm{M}\right)$ of benzylviologen $(\boldsymbol{a})$, TCNQ $(\boldsymbol{b})$ and TCNE $(\boldsymbol{c})$ recorded with bare gold working electrodes. 


\section{Determination of $\boldsymbol{R}_{\mathrm{CT}}$ from the Impedance Plots}

The charge-transfer resistances $\left(R_{\mathrm{CT}}\right)$ were determined by analyzing the semi-circular regions of the impedance plots in Figures 5, 7 and S3. Indeed, the impedance profile in these regions can be modeled with an equivalent circuit (Figure S4) incorporating two resistors and a constant phase element. ${ }^{4}$ The two resistors represent the ohmic solution resistance $\left(R_{\Omega}\right)$ and $R_{\mathrm{CT}}$. The impedance $\left(\mathrm{Z}_{\mathrm{CPE}}\right)$ of the constant-phase element is related to the frequency $(\omega)$ of the alternating voltage and the imaginary unit ( $j$ ) according to equation (1). The parameters $\alpha$ and $\sigma$ are the exponent and coefficient of the constant-phase element respectively. In ideal systems, $\alpha$ is unity and $\sigma$ corresponds to the double-layer capacitance. Under these conditions, the constant-phase element is

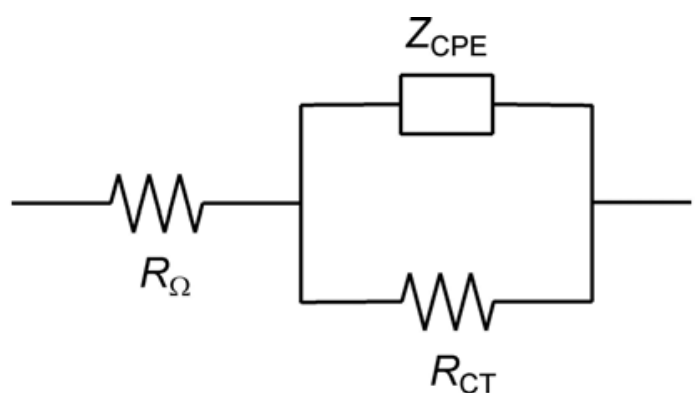

Figure S6. Circuit equivalent to the semicircular regions of the impedance plots. equivalent to a capacitor and the circuit in Figure S4 reduces to Randles

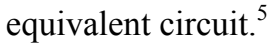

Equation (2) relates the total impedance $\left(Z_{\mathrm{T}}\right)$ of the equivalent circuit (Figure $\left.\mathrm{S} 4\right)$ to the resistances $\left(R_{\Omega}\right.$ and $\left.R_{\mathrm{CT}}\right)$ and impedance $\left(Z_{\mathrm{CPE}}\right)$ of its components. Equation (3) defines the real $\left(Z^{\prime}\right)$ and imaginary $\left(Z^{\prime \prime}\right)$ parts of the vector $Z_{\mathrm{T}}$. After combining equations (1-3), $Z^{\prime}$ and $Z^{\prime \prime}$ can be expressed as functions of $\omega(4$ and 5). The two parameters $x$ and $y$ are related to the constant-phase element terms $\alpha$ and $\sigma$ according to equations (6) and (7).

Experimental plots of $Z^{\prime}$ and $Z^{\prime \prime}$ against $\omega$ can be fitted to equations (4) and (5) using a curve-fitting program. ${ }^{6}$ This analysis provides reliable estimates of the parameters $R_{\Omega}, R_{\mathrm{CT}}, \alpha$ and $\sigma$. The fittings of the impedance plots of benzylviologen, TCNQ, TCNE and $\mathrm{Ru}\left(\mathrm{NH}_{3}\right)_{6} \mathrm{Cl}_{3}$ are shown in Figures 5, 7 and S3. In all cases, the coefficient of determination (COD) for the fitting was greater than 0.99 (Tables $\mathrm{S} 1$ and $\mathrm{S} 2$ ) with standard deviations for $R_{\mathrm{CT}}$ smaller than $0.5 \%$.

$$
\begin{aligned}
& Z_{\mathrm{CPE}}=\sigma^{-1}(j \omega)^{-\alpha} \\
& Z_{\mathrm{T}}=R_{\Omega}+\frac{Z_{\mathrm{CPE}} R_{\mathrm{CT}}}{Z_{\mathrm{CPE}}+R_{\mathrm{CT}}} \\
& Z_{\mathrm{T}}=Z^{\prime}-j Z^{\prime \prime} \\
& Z^{\prime}=R_{\Omega}+\frac{R_{\mathrm{CT}}^{2} x \omega^{-\alpha}+R_{\mathrm{CT}} \omega^{-2 \alpha} \sigma^{-2}}{\left(R_{\mathrm{CT}}+x \omega^{-\alpha}\right)^{2}+y^{2} \omega^{-2 \alpha}} \\
& Z^{\prime \prime}=\frac{\left(R_{\mathrm{CT}}+x \omega^{-\alpha}\right)^{2}+y^{2} \omega^{-2 \alpha}}{\operatorname{Cos} \frac{\alpha \pi}{2}} \\
& x=\sigma^{-1} \cos \omega^{-\alpha} \\
& y=\sigma^{-1} \sin \frac{\alpha \pi}{2}
\end{aligned}
$$

4 Pajkossy, T. J. Electroanal. Chem. 1994, 364, 111-125.

5 Bard, A. J.; Faulkner, L. R. Electrochemical Methods: Fundamentals and Applications; Wiley: New York, 2001.

6 PSI-Plot 7.5, Poly Software International, Pearl River, NY, 2003. 
Table S1. Parameters determined by fitting the semi-circular regions of the impedance plots recorded with hexadecanethiolate-coated gold electrodes to equations (4) and (5).

\begin{tabular}{|c|c|c|c|c|c|}
\hline Compound & $R_{\Omega}(\mathrm{k} \Omega)$ & $R_{\mathrm{CT}}(\mathrm{k} \Omega)$ & $\alpha$ & $\sigma\left(\mathrm{k} \Omega^{-1} \mathrm{~Hz}^{-\alpha}\right)$ & COD \\
\hline Benzylviologen $^{a, b}$ & $0.20 \pm 0.06$ & $26.3 \pm 0.3$ & $0.790 \pm 0.008$ & $0.00139 \pm 0.00005$ & 0.9974 \\
\hline $\mathrm{TCNE}^{a, c}$ & $0.194 \pm 0.004$ & $1.55 \pm 0.04$ & $0.77 \pm 0.01$ & $0.0123 \pm 0.0008$ & 0.9968 \\
\hline $\mathrm{Ru}\left(\mathrm{NH}_{3}\right)_{6} \mathrm{Cl}_{3}{ }^{d}$ & $0.2 \pm 0.1$ & $86.8 \pm 0.4$ & $0.77 \pm 0.01$ & $0.00380 \pm 0.00004$ & 0.9989 \\
\hline
\end{tabular}

${ }^{a}$ The experimental plots $\left(0.1 \mathrm{M} \mathrm{Bu}_{4} \mathrm{NPF}_{6}, \mathrm{MeCN}, \mathrm{V}\right.$ vs. $\left.\mathrm{Ag} / \mathrm{AgCl}, 100 \mathrm{kHz}-0.1 \mathrm{~Hz}\right)$ and fittings are shown in Figures 5 and 7. ${ }^{b}-0.316 \pm 0.005 \mathrm{~V} .{ }^{c}+0.292 \pm 0.005 \mathrm{~V} .{ }^{d}$ The experimental plot $\left(0.1 \mathrm{M} \mathrm{KCl}, \mathrm{H}_{2} \mathrm{O},-0.133 \pm 0.005 \mathrm{~V}\right.$ vs. $\mathrm{Ag} / \mathrm{AgCl}, 100 \mathrm{kHz}-0.1 \mathrm{~Hz}$ ) and fitting are shown in Figure S3.

Table S2. Parameters determined by fitting the semi-circular regions of the impedance plots recorded with TTF-coated gold electrodes to equations (4) and (5). ${ }^{a}$

\begin{tabular}{lccccc}
\hline \multicolumn{1}{c}{ Compound } & $R_{\Omega}(\mathrm{k} \Omega)$ & $R_{\mathrm{CT}}(\mathrm{k} \Omega)$ & $\alpha$ & $\sigma\left(\mathrm{k} \Omega^{-1} \mathrm{~Hz}^{-\alpha}\right)$ & $\mathrm{COD}$ \\
\hline Benzylviologen $^{b}$ & $0.8 \pm 0.2$ & $324 \pm 1$ & $0.647 \pm 0.003$ & $0.00263 \pm 0.00001$ & 0.9996 \\
$\mathrm{TCNQ}^{c}$ & $0.13 \pm 0.05$ & $24.3 \pm 0.1$ & $0.745 \pm 0.005$ & $0.00171 \pm 0.00004$ & 0.9990 \\
$\mathrm{TCNE}^{d}$ & $0.43 \pm 0.08$ & $42.7 \pm 0.2$ & $0.820 \pm 0.005$ & $0.00140 \pm 0.00003$ & 0.9988 \\
\hline
\end{tabular}

${ }^{a}$ The experimental plots $\left(0.1 \mathrm{M} \mathrm{Bu}_{4} \mathrm{NPF}_{6}, \mathrm{MeCN}, \mathrm{V}\right.$ vs. $\left.\mathrm{Ag} / \mathrm{AgCl}, 100 \mathrm{kHz}-0.1 \mathrm{~Hz}\right)$ and fittings are shown in Figures 5 and 7. ${ }^{b}-0.316 \pm 0.005 \mathrm{~V} .{ }^{c}+0.249 \pm 0.005 \mathrm{~V} .{ }^{d}+0.292 \pm 0.005 \mathrm{~V}$. 